\title{
A characterization of the antimalarial activity of the bark of Cylicodiscus gabunensis Harms
}

Omar Aldulaimi ${ }^{1,}{ }^{2}$, Fidelia I. Uche ${ }^{1}$, Hamza Hameed ${ }^{1}$, Haddijatou Mbye ${ }^{1}$, Imran Ullah ${ }^{1}$, Falko Drijfhout $^{3}$, Timothy D.W. Claridge ${ }^{4}$, Paul Horrocks ${ }^{1}$, Wen-Wu Li ${ }^{1 *}$

${ }^{1}$ Institute for Science and Technology in Medicine, Keele University, Staffordshire ST5 5BG, United Kingdom

${ }^{2}$ College of Pharmacy, Al-Mustansiriyah University, Baghdad, Iraq

${ }^{3}$ Chemical Sciences Research Centre, Keele University, Staffordshire ST5 5BG, United Kingdom

${ }^{4}$ Chemical Research Laboratory, University of Oxford, Oxford OX1 3TA, United Kingdom

*Corresponding authors:

Dr. Wen-Wu Li

E-mail: w.li@keele.ac.uk

Phone: +44 (0)1782 674382

Fax: $\quad+44(0) 1782747319$ 
Keywords: Cylicodiscus gabunensis; malaria; gallic acid; oligosaccharide conjugates; structural elucidation.

Abbreviations: CG, Cylicodiscus gabunensis Harms; CGE, ethanol extract of CG; CGH, hexane extract of CG; CGEEA, ethyl acetate fraction of CGE; CGEBU, n-butanol fraction of CGE; CGEAQ, aqueous fraction of CGE; GC-MS, gas chromatography mass spectrometry; LC-MS, liquid chromatography mass spectrometry; NMR, nuclear magnetic resonance; TMS, trimethylsilyl; WHO, World Health Organization 


\section{Abstract}

Ethnopharmacological relevance and aim: A decoction of the bark of Cylicodiscus gabunensis Harms is used as a traditional medicine in the treatment of malaria in Nigeria. This study aims to validate the antimalarial potency of this decoction in vitro against Plasmodium falciparum and define potential bioactive constituents within the C. gabunensis bark.

Materials and methods: A bioassay-guided separation and fractionation protocol was applied to $C$. gabunensis extracts, exploiting the use of a Malaria Sybr Green I Fluorescence assay method to monitor antiproliferative effects on parasites as well as define $50 \%$ inhibition concentrations. Spectroscopic techniques, including GC-MS, TOF LC-MS and ${ }^{1} \mathrm{H}$ NMR were used to identify phytochemicals present in bioactive fractions. Analogues of gallic acid were synthesized de novo to support the demonstration of the antimalarial action of phenolic acids identified in C. gabunensis bark. In vitro cytotoxicity of plant extracts, fractions and gallate analogues was evaluated against the HepG2 cell line.

Results: The antimalarial activity of ethanolic extracts of C. gabunensis bark was confirmed in vitro, with evidence for phenolic acids, primarily gallic acid and close analogues such as ethyl gallate, likely providing this effect. Further fraction produced the most potent fraction with a 50\% inhibitory concentration of $4.7 \mu \mathrm{g} / \mathrm{ml}$. Spectroscopic analys is, including ${ }^{1} \mathrm{H}$ NMR, LC-MS and GC-MS analysis of this fraction and its acid hydrolyzed products, indicated the presence of conjugates of gallic acid with oligosaccharides. The extracts/fractions and synthetic alkyl gallate showed moderate selectivity aga inst $P$. falciparum.

Conclusions: These results support the use of the bark of C.gabunensis as a traditional medicine in the treatment of human malaria, with phenolic acid oligosaccharide complexes evident in the most bioactive fractions. 


\section{Introduction}

Malaria imposes a significant health and socioeconomic impact within endemic regions across tropical and subtropical zones. In 2015 the World Health Organization (WHO) estimated there were some 214 million new cases of malaria globally, resulting in approximately 438,000 deaths. Of these deaths, some 90\% occur within Sub-Saharan Africa (WHO, 2015). Yet over the last 15 years, the incidence of malaria and mortality figures, particularly in Africa, are falling significantly (Bhatt et al., 2015). This success follows from the introduction of interventions such as indoor residual spraying and insecticide treated bed nets, improved access to rapid diagnostic testing and the adoption of artemisinin combination therapies as the frontline antimalarial treatment. However, these successes are mirrored by increasing evidence of the development and spread of insecticide resistance and reports of artemisinin resistance within South East Asia (Ashley et al, 2014). The continued search for novel compounds with modes of action distinct to those of the current antimalarial pharmacopeia, include efforts to build on the success of plant-derived natural products, and their semi-synthetic analogues, in contributing new antimalarial leads. Traditional medicines have proven important in this search, with their importance demonstrated by the WHO which estimates that some $80 \%$ of populations in resource-poor regions depend upon these traditional medic ines for antimalarial treatment.

Cylicodiscus gabunensis Harms (CG) (Leguminosae) is a medic inal plant used for the treatment of fever, internal abscess, jaundice and malaria by the Ibibio of the Niger Delta region of Nigeria (Okokon et al., 2006). The ethanolic stem bark extract of $C$. gabunensis shows schizontocidal activity in both early and established Plasmodium berghei infections in mice, with treatment showing an improved survival time comparable to that of chloroquine (Okokon et al., 2006). To date, several phytochemical studies on this plant have indicated the presence of triterpenes such as cylicodiscic acid (Tchivounda et al., 1990), triterpenoid saponins (Mkounga et al., 2010; Tchivounda et al., 1991; Tene et al., 2011) and cyclodione (Tane et al., 1995). However, the antimalarial compounds in the plant extract are still unknown. In this study, we confirm that extracts of $C$. gabunensis possess in vitro inhibitory effects against the blood 
stages of the human malarial parasite $P$. falciparum Dd2, using a bioassay-guided fractionation procedure to isolate fractions which were then subjected to spectroscopic methods to identify compounds with potential antimalarial activity. Our studies suggest that phenolics, such as gallic acid and its derivatives may provide the active antimalarial constituent in C. gabunensis bark extracts. Furthermore, it is apparent that within the most potent fractions that phenolic-oligosaccharide conjugates likely provide the source of antimalarial potency.

\section{Materials and methods}

\subsection{Plant materials and chemicals}

The bark of C. gabunensis was collected from the Imo state, Nigeria in September 2011. The plant was identified by Mr. H. Donyeachusim and a voucher specimen (UPH1028) was kept in the herbarium at the University of Port Harcourt, Nigeria. Solvents were supplied by Fischer Scientific (UK), other chemical were sourced from Sigma-Aldrich (UK).

\subsection{Extraction of plant materials}

Powdered C. gabunensis bark (120 g) was macerated over 48hrs in two liters of hexane, the process repeated and the filtrates combined and evaporated at $30^{\circ} \mathrm{C}$ under vacuum to yield the hexane extract (CGH, $0.9 \mathrm{~g}, 0.75 \%$ ). The residue was extracted again by maceration using the same procedure with 70\% ethanol; the filtrates were combined and dried at $45^{\circ} \mathrm{C}$ under vacuum to give the ethanol extract (CGE, 11.3 g, $9.4 \%)$.

\subsection{Fractionation and separation of bioactive compounds}

CGE (11 g) was dissolved in 700ml deionized water and partitioned with ethyl acetate and n-butanol sequentially to give the ethyl acetate fraction (CGEEA, 0.9g), butanol fraction (CGEBU, 8.3g) and aqueous fraction (CGEAQ, 1.6g). The CGEBU fraction was further fractionated on a silica gel glass column (35-75 $\mu \mathrm{m} ; 4 \times 60 \mathrm{~cm}$ ) washed with solvent system $\mathrm{CHCl}_{3} / \mathrm{MeOH} / \mathrm{H}_{2} \mathrm{O}(10: 1: 0.1)$ with increasing methanol (final concentration 100\%) at a flow rate of $3 \mathrm{ml} / \mathrm{min}$ to give 10 pooled fractions (CGEBU-F(1- 
10)). Further separation of CGEBU-F10 was performed using preparative HPLC, yielding 8 sub-fractions CGEBU-F10-(1 to 8). A full description of the preparative HPLC is provided in the Supplementary materials.

\subsection{Spectroscopic and chemical analysis}

A full description of acid hydrolysis method, gas chromatography mass spectrometry (GC-MS), liquid chromatography mass spectrometry (LC-MS) and proton nuclear magnetic resonance $\left({ }^{1} \mathrm{H}\right.$ NMR) spectroscopic analysis are provided in the Supplementary materials.

\subsection{Chemical synthesis of gallic acid derivatives}

Gallic acid and other phenolic acids were purchased from Sigma-Aldrich (UK). In addition, five gallic acid derivatives (Table 1) were prepared de novo for this study. Their synthesis and spectroscopic analysis is described in the Supplementary materials.

\subsection{In vitro determination of antimalarial activity}

The in vitro antimalarial activities of the plant extracts, fraction or pure compounds were assessed against intraerythrocytic P. falciparum culture (Dd2 strain) using the Sybr Green l Fluorescence assay as described (Smilkstein et al., 2004) and modified (Hasenkamp et al., 2013). CGE and its three fractions CGEEA, CGEBU, CGEAQ; CGH; and CGEBU-F1-10 were prepared as three concentrations in DMSO (100, 33.3, and $11.1 \mu \mathrm{g} / \mathrm{ml}$ ) with DMSO not greater than $1 \%$ of the total concentration, while the most active fractions CGEBU-F10 and CGEBU-F10-7 were prepared using a serial two-fold dilution (200, $100,50,25,12.5,6.25,3.13,1.56$, and $0.78 \mu \mathrm{g} / \mathrm{ml})$. Normalized fluorescence signals were determined against controls with 1\% DMSO (100\% growth) and exposure to a supralethal 10 $\mathrm{MM}$ dose of chloroquine (0\%growth). Determination of the $50 \%$ inhibitory concentration $\left(\mathrm{IC}_{50}\right)$ was carried out with analys is of a log transformed concentration versus normalized fluorescence effect curve using GraphPad Prism software (v5.0) on data prepared from three independent biological replicates.

\subsection{In vitro cytotoxicity against HepG2 cells}

The in vitro activities of the plant extracts, fraction or pure compounds were assessed against HepG2 (human liver carcinoma) using a modified alamar blue fluorescence assay as described (Horrocks et al, 
2013). HepG2 cells were maintained in DMEM media supplemented with $10 \%$ (v/v) foetal bovine serum and $0.2 \%(\mathrm{v} / \mathrm{v})$ of a penicillin $(10 \mathrm{U} / \mathrm{ml}) /$ streptomyc in $(10 \mu \mathrm{g} / \mathrm{ml})$ solution at $37^{\circ} \mathrm{C}$ in an atmosphere of $5 \% \mathrm{CO}_{2} .100 \mu \mathrm{L}$ of cell suspension of HepG2 cells were seeded into a 96-well microplate at a density of $1 \times 10^{5} \mathrm{cells} / \mathrm{ml}$. After $24 \mathrm{~h}$ of growth at $37^{\circ} \mathrm{C}, 100 \mu \mathrm{l}$ of extracts or compounds in medium were added to the microplate wells, starting at either $150 \mathrm{mM}$ or $150 \mu \mathrm{g} / \mathrm{ml}$, to provide a twofold dilution series. Untreated controls were provided by cultures exposed to a 1\% DMSO (100\% growth) with a drug-treated control provided by exposure to $500 \mathrm{nM}$ actinomycin $\mathrm{D}$ ( $0 \%$ growth). The microplate was incubated at $37^{\circ} \mathrm{C}$ for a further $48 \mathrm{hrs}$ before the cellular reductase activity was measured using an alamar blue ${ }^{\circledR}$ cell viability reagent (ThermoFisher). $20 \mu \mathrm{L}$ of alamar blue was added into each well and mixed by shaking the plate. The fluorescence signal was measured at $570 \mathrm{~nm}$ using a Glomax multi-detection System after 6 hours incubation. The 50\% cytotoxicity concentration $\left(\mathrm{CC}_{50}\right)$ was determined by analysis of a $\log$ transformed concentration versus normalized fluorescence signal curve using GraphPad Prism software (v5.0).

\section{Results}

\subsection{Bioassay guided separations of extract of Cylicodiscus gabunensis bark}

A sample of $C$. gabunensis bark was extracted sequentially into hexane and 70\% ethanol to produce CGE and CGH extracts. The anti-proliferative activity of these extracts was determined using in vitro growth inhibition assays of the Dd2 strain (chloroquine resistant) of P. falciparum, Chloroquine was used as a positive control (Table 1). Given the apparently greater antimalarial activity of CGE (IC $5020.8 \mu \mathrm{g} / \mathrm{ml}$ ), further fractional separation in ethyl acetate (CGEEA), butanol (CGEBU) and water (CGEAQ) was undertaken. Here, the CGEBU fraction showed an approximate two-fold increase in antimalarial action over CGE ( IC $\left._{50} 10.4 \mu \mathrm{g} / \mathrm{ml}\right)$. The CGEBU fraction was subjected to column chromatography to yield 10 sub-fractions, with fraction CGEBU-F10 the most potent with an $\mathrm{IC}_{50}$ of $6.5 \mu \mathrm{g} / \mathrm{ml}$. CGEBU-F10 was further separated using preparative HPLC (Figure S1) to yield eight sub-fractions. Of these, CGEBU-F10- 
7 was the most active, providing an $\mathrm{IC}_{50}$ of $4.7 \mu \mathrm{g} / \mathrm{ml}$. Figure 1 shows a summary of the bioassay fractionation strategy employed. The cytotoxic ity of CGE, CGEBU and CGEBU-F10 decreased in turn, with concurrent increases in antiplasmodial activity, although the selectivity (Selective index, SI $\mathrm{CC}_{50} / \mathrm{IC}_{50}$ ) against HepG2 cells only reached a modest value of $>23$. Insufficient CGEBU-F10-7 was available for cytotoxivity assays.

\section{Cyclodiscus gabunensis (CG) bark}

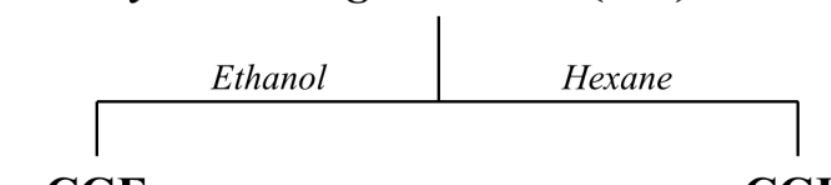

\section{CGE}

$20.8 \mu \mathrm{g} / \mathrm{ml}$

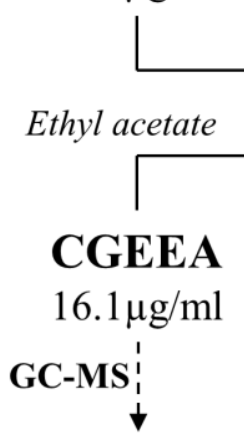

Gallic acid

Vanillic acid

Protocatechuic acid

Ethyl gallate

4-hydroxy-benzoic acid

Syringic acid

Fatty acids

\section{CGH}

$32.1 \mu \mathrm{g} / \mathrm{ml}$

Water

\section{CGEAQ \\ $25.8 \mu \mathrm{g} / \mathrm{ml}$ \\ CGEBU \\ $10.4 \mu \mathrm{g} / \mathrm{ml}$}

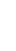


are indicated using italics, with the $\mathrm{IC}_{50}$ of derived fractions indicated below each. Further column chromatography (generating 10 pooled fractions) of CGEBU and HPLC fractionation (8 pooled fractions) of CGEBU-F10 were used to derive the most potent fraction, CGEBU-F10-7. Where indicated with dotted lines, the spectroscopic methods listed were used to identify the key phytochemical components.

In order to identify potentially bioactive compounds, GC-MS was initially applied to both CGEEA and CGEBU fractions after trimethylsilylation (Johnson-Ajinwo et al., 2015). These analyses (Figures S2 and S3; Table S1 and S2), indicate that 3,4,5-trihydroxybenzoic acid (gallic acid) as well as several fatty acids were present in both the CGEEA and CGEBU extracts, but also that additional benzoic acid derivatives, including 3-methoxy-4-hydroxybenzoic acid (vanillic acid, 0.4\%), 3,4-dihydroxybenzoic acid (protocatechuic acid, 2\%), and 3,4,5-trihydroxybenzoic ethyl ester (ethyl gallate, 2\%), were also present in CGEEA.

Independent confirmation of the potency of these benzoic acid derivatives was provided through additional growth inhibition assays of P. falciparum using commercially sourced materials (Table 1). These results indicated that either loss of a phenol group (e.g. vanillic acid) or substitutions to phenol groups of gallic acid (e.g. 3-methoxy-4-hydroxybenzoic acid or 3,4,5-trimethoxybenzoic acid) led to a decrease in antimalarial potency. Of note was the similar potency of ethyl gallate and propyl gallate to gallic acid, although these esterified derivatives are significantly less hydrophilic based on their predicted partition coefficients (LogP) (Table 1). To further explore this structure activity relationship, five additional esters were synthesized (Table 1, Table S3 and S4, Figure S4, and Supplementary materials), using gallic acid as a precursor, and their in vitro potency determined. These data indicate that whilst most have an $\mathrm{IC}_{50}$ comparable to that of ethyl gallate or propyl gallate, lauryl gallate, the most lipophilic derivative, was much lower at $2.2 \mu \mathrm{M}$, some 6-7 fold less than that of gallic acid. Unfortunately, the selectivity of these gallic acid derivatives remained only modest at best (Table 1) with alkyl and alkenyl gallates showed the best selectivity with selective indices between 10 and $>17$. 
Table 1. In vitro antiplasmodial activity ( $\left.\mathrm{IC}_{50}\right)$ and cytotoxic ity $\left(\mathrm{CC}_{50}\right)$ against HepG2 cells of extracts, fraction, gallic acid and its derivatives (along with standard deviation, SD, based on three biological repeats). Names of commercially sourced compounds or those synthesized (marked with*, Supplementary material) for this study are listed. Selective index, SI, is calculated as $\mathrm{CC}_{50} / \mathrm{IC}_{50}$. The LogP of compounds was predicted using Chemdraw software (PerkinElmer, USA). nd, not determined.

\begin{tabular}{|c|c|c|c|c|}
\hline Extract/fraction/compound & $\mathrm{IC}_{50} \pm \mathrm{SD}$ & $\mathrm{CC}_{50} \pm \mathrm{SD}$ & SI & $\log \mathrm{P}$ \\
\hline & $(\mu \mathrm{g} / \mathrm{ml})$ & $(\mu \mathrm{g} / \mathrm{ml})$ & & \\
\hline CGE & $20.8 \pm 1.8(\mu \mathrm{g} / \mathrm{ml})$ & $59.8 \pm 14(\mu \mathrm{g} / \mathrm{ml})$ & 2.9 & nd \\
\hline CGEBU & $10.4 \pm 1.9(\mu \mathrm{g} / \mathrm{ml})$ & $50.1 \pm 5.2(\mu \mathrm{g} / \mathrm{ml})$ & 4.8 & nd \\
\hline CGEBU-F10 & $6.5 \pm 0.6(\mu \mathrm{g} / \mathrm{ml})$ & $>150(\mu \mathrm{g} / \mathrm{ml})$ & $>23$ & nd \\
\hline \multirow[t]{2}{*}{ CGEBU-F10-7 } & $4.7 \pm 0.4(\mu \mathrm{g} / \mathrm{ml})$ & nd & nd & nd \\
\hline & $(\mu \mathrm{M})$ & $(\mu \mathrm{M})$ & & \\
\hline Gallic acid & $26.8 \pm 4.4$ & $11 \pm 1$ & 0.4 & 0.42 \\
\hline 3,4-Dihydroxybenzoic acid & $83.4 \pm 10.0$ & $>150$ & $>1.8$ & 0.81 \\
\hline 3-Methoxy-4-hydroxybenzoic & $71.2 \pm 11.0$ & $>150$ & $>2.1$ & 1.08 \\
\hline \multicolumn{5}{|l|}{ acid } \\
\hline 3,4,5-Trimethoxybenzoic acid & $112.3 \pm 15.2$ & $>150$ & $>1.3$ & 1.21 \\
\hline Ethyl gallate & $9.3 \pm 3.1$ & $>150$ & $>16.1$ & 1.02 \\
\hline Propyl gallate & $24.5 \pm 2.9$ & $>150$ & $>6.1$ & 1.51 \\
\hline Propan-2-yl gallate* & $13.9 \pm 1.8$ & $>150$ & $>10.8$ & 1.34 \\
\hline 2-Methylpropyl gallate* & $16.9 \pm 2.3$ & $78 \pm 20$ & 4.6 & 1.91 \\
\hline 2-Methylbutyl gallate* & $11.8 \pm 1.2$ & $38 \pm 10$ & 3.2 & 2.33 \\
\hline 3-Methylbut-2-en-1-yl gallate* & $17.5 \pm 2.2$ & $87 \pm 16$ & 5.0 & 1.92 \\
\hline 3-Methylbutyl gallate* & $8.8 \pm 1.5$ & $>150$ & $>17.0$ & 2.26 \\
\hline Lauryl gallate & $2.2 \pm 0.2$ & $30 \pm 2$ & 13.6 & 5.27 \\
\hline Chloroquine & $0.17 \pm 0.02$ & nd & nd & 5.00 \\
\hline Actinomycin D & nd & $0.0038 \pm 0.0013$ & nd & 3.80 \\
\hline
\end{tabular}




\subsection{Structural elucidation of the phytochemical content of CGEBU10-7}

GC-MS analysis of trimethylsilyl (TMSi) derivatives of CGEBU-F10-7 did not produce resolvable spectra, suggesting that the masses of the phytochemicals present were greater than that readily discernable using this approach. This was confirmed using an alternative LC-MS approach that revealed a complex mixture of compounds with masses ranging between 1000 and 1500 Da (Figure S5). Thus, the CGEBU-F10-7 fraction was subjected to acid hydrolysis, with GC-MS of the TMSi derivatives of these hydrolysed products carried out (Figure S6). This approach revealed the presence of gallic acid as well as three pairs of isomeric monosaccharides: $\alpha$ - and $\beta$-L-arabinose; $\alpha$ - and $\beta$-L-rhamnose; and $\alpha$ - and $\beta$-Lglucose. It was considered likely that the acid hydrolys is procedure led to the anomerization of these sugars, which was subsequently conf irmed in a subsequent experiment using commercially sourced sugar standards in water at $100^{\circ} \mathrm{C}$. In addition, ${ }^{1} \mathrm{H}$ NMR (Figure S7) of CGEBU-F10-7 was carried out, revealing multiple peaks in the regions of $\delta$ 6-8 ppm and $\delta$ 3-6 ppm, supporting the existence of aromatic and sugar moieties in this complex fraction. In particular, two doublets at $\delta 5.2(\mathrm{~d}, J=3.7 \mathrm{~Hz})$ and $\delta 4.4$ $(\mathrm{d}, J=7.6 \mathrm{~Hz})$ would support the presence of anomeric protons of $\alpha$-L-arabinosyl and $\beta$-Dglucopyranosyl moiety, respectively (Tene et al., 2011). Together, these data suggest the presence of gallic acid - oligosaccharide conjugates within the CGEBU-F10-7 fraction.

\section{Discussion}

Using a comprehensive bioassay-guided fractionation and isolation of the bark of C. gabunensis we provide evidence for the presence of antimalarial activity of both crude extracts, correlating with the previous observation of activity of an ethanolic extract against the murine malaria $P$. berghei (Okokon et al., 2006), but also refine this activity further to demonstrate specific activity of phenolic acids present in CGEBU and CGEEA. A preliminary structure activity relationship study of benzoic acid and gallate derivatives, including several synthesized de novo for this study, indicate that free hydroxyl groups on the aromatic ring for gallic acid and gallate esters are essential for their antimalarial effect. Gallic acid and

protocatechuic acid have both previously been shown to moderate antimalarial activities against 
chloroquine-resistant $P$. falciparum strain W2 (Garcia-Alvarez et al., 2013) with an additional study using ethyl gallate reporting an in vitro antiplasmodial effect of $\mathrm{IC}_{50}$ between 9 - $35 \mu \mathrm{M}$ (Ramanandraibe et al., 2008). Results from these previous studies were in agreement with our own, with our study further suggesting that alkyl gallates, in particular lauryl gallate, have a greater antiplasmodial activity than ga llic acid itself (Table 1). These promising observations, however, are moderated by the apparent restricted selectivity of these phenolic acids as compared to the HepG2 cell line.

Bioassay guided fractionation gave a HPLC fraction (CGEBU-F10-7) which was most active. LC-MS, GC-MS and ${ }^{1} \mathrm{H}$ NMR analysis suggested that conjugates of oligosaccharide with gallic acid may be present in this fraction. However, the exact linkage between the monosaccharides and gallic acid needs further detailed study. Previously an oligosaccharide derivative (a resin glycoside, crypthophilic acid C) from Scrophularia cryptophila showed antimalarial activity with $\mathrm{IC}_{50}$ value of $4.2 \mu \mathrm{g} / \mathrm{ml}$ (Tasdemir et al., 2008). Ellagic acid (a dimer of gallic acid) and a galloyl glycoside from Tristaniopsis calobuxus bark extract had $\mathrm{IC}_{50}$ values of 0.5 and $3.2 \mu \mathrm{M}$, respectively (Verotta et al., 2001). 1-O-galloyl-6-O-luteoyl- $\alpha$ D-glucose from Phyllanthus niruri also showed very low $\mathrm{IC}_{50}(1.4 \mu \mathrm{g} / \mathrm{ml})$ (Subeki et al., 2005). Together with our own data, these observations suggest that a galloyl moiety within the bark of C. gabunensis likely supplies the observed antimalarial activity of this traditional medicine.

\section{Conclusions}

Bioassay guided fractionation of C. gabunensis extract yielded fractions with increasing antimalarial activity and selectivity of action. Using spectroscopic and chemical methods, gallic acid, ethyl gallate and benzoic acids were demonstrated to be present and likely contributed to this antimalarial activity. The likely bioactive component in this traditional medicine for the treatment of malaria is a galloyl glycoside conjugate. 


\section{Acknowledgments}

We are grateful for Ph.D. scholarships to Mr. Omar Aldulaimi and Ms. Fidelia Uche from MOHSER/IRAQ, ETF Nigeria, respectively. We also thank Bridging the Gaps MRC Centenary Award (WWL and PH).

\section{Appendix A. Supplementary information}

Supplementary data associated with this article can be found in the online version.

\section{References}

Ashley, E.A., Dhorda, M., Fairhurst, R.M., Amaratunga, C., Lim, P., Suon, S., Sreng, S., Anderson, J.M., Mao, S., Sam, B., Sopha, C., Chuor, C.M., Nguon, C., Sovannaroth, S., Pukrittayakamee, S., Jittamala, P., Chotivanich, K., Chutasmit, K., Suchatsoonthorn, C., Runcharoen, R., Hien, T.T., Thuy-Nhien, N.T., Thanh, N.V., Phu, N.H., Htut, Y., Han, K.T., Aye, K.H., Mokuolu, O.A., Olaosebikan, R.R., Folaranm,i O.O., Mayxay, M., Khanthavong, M., Hongvanthong, B., Newton, P.N., Onyamboko, M.A., Fanello, C.I., Tshefu, A.K., Mishra, N., Valecha, N., Phyo, A.P., Nosten, F., Yi, P., Tripura, R., Borrmann, S., Bashraheil, M., Peshu, J., Faiz, M.A., Ghose, A., Hossain, M.A., Samad, R., Rahman, M.R., Hasan, M.M., Islam, A., Miotto, O., Amato, R., MacInnis, B., Stalker, J., Kwiatkowski, D.P., Bozdech, Z., Jeeyapant, A., Cheah, P.Y., Sakulthaew, T., Chalk. J., Intharabut, B., Silamut, K., Lee, S.J., Vihokhern, B., Kunasol. C., Imwong, M., Tarning, J., Taylor, W.J., Yeung, S., Woodrow, C.J., Flegg, J.A., Das, D., Smith, J., Venkatesan, M., Plowe, C.V., Stepniewska, K., Guerin, P.J., Dondorp, A.M., Day, N.P., White, N.J. Tracking Resistance to Artemisinin Collaboration (TRAC), 2014. Spread of artemisinin resistance in Plasmodium falciparum malaria. New Engl J Med 371, 411-423.

Bhatt, S., Weiss, D.J., Cameron, E., Bisanzio, D., Mappin, B., Dalrymple, U., Battle, K.E., Moyes, C.L., Henry, A., Eckhoff, P.A., Wenger, E.A., Briët, O., Penny, M.A., Smith, T.A., Bennett, A., Yukich, J., Eisele, T.P., Griffin, J.T., Fergus, C.A., Lynch, M., Lindgren, F., Cohen, J.M., Murray, C.L., Smith, D.L., 
Hay, S.I., Cibulskis, R.E., Gething, P.W., 2013. The effect of malaria control on Plasmodium falciparum in Africa between 2000 and 2015. Nature 526, 207-211.

Garcia-Alvarez, M.C., Moussa, I., Soh, P.N., Nongonierma, R., Abdoulaye, A., Nicolau-Travers, M.L., Fabre, A., Wdzieczak-Bakala, J., Ahond, A., Poupat, C., Ikhiri, K., Benoit-Vical, F., 2013. Both plants Sebastiania chamaelea from Niger and Chrozophora senegalensis from Senegal used in African traditional medicine in malaria treatment share a same active principle. J Ethnopharmacol 149, 676-684. Hasenkamp, S., Sidaway, A., Devine, O., Roye, R., Horrocks, P., 2013. Evaluation of bioluminescencebased assays of anti-malarial drug activity. Malar J 12, 58.

Horrocks, P., Pickard, M.R., Parekh,H.H., Patel, S.P., Pathak, R.B., 2013. Synthesis and biological evaluation of 3-(4-chlorophenyl)-4-substituted pyrazole derivatives. Org Biomol Chem 11, 4891-4898.

Johnson-Ajinwo, O.R., Richardson, A., Li, W.W., 2015. Cytotoxic effects of stern bark extracts and pure compounds from Margaritaria discoidea on human ovarian cancer cell lines. Phytomedicine 22, 1-4.

Mkounga, P., Tiabou, A.T., Kouam, J., 2010. Triterpenoid Derivatives from Cylicodiscus gabunensis. Chem Pharm Bull 58, 1100-1102.

Okokon, J.E., Ita, B.N., Udokpoh, A.E., 2006. Antiplasmodial activity of Cylicodiscus gabunensis. J Ethnopharmacol 107, 175-178.

Ramanandraibe, V., Grellier, P., Martin, M.T., Deville, A., Joyeau, R., Ramanitrahasimbola, D., Mouray, E., Rasoanaivo, P., Mambu, L., 2008. Antiplasmodial phenolic compounds from Piptadenia pervillei. Planta Med 74, 417-421.

Smilkstein, M., Sriwilaijaroen, N., Kelly, J.X., Wilairat, P., Riscoe, M., 2004. Simple and inexpensive fluorescence-based technique for high-throughput antimalarial drug screening. Antimicrob Agents Chemother 48, 1803-1806.

Subeki, S., Matsuura, H., Takahashi, K., Yamasaki, M., Yamato, O., Maede, Y., Katakura, K., Kobayashi, S., Trimurningsih, T., Chairul, C., Yoshihara, T., 2005. Anti-babesial and anti-plasmodial compounds from Phyllanthus niruri. J Nat Prod 68, 537-539. 
Tane, P., Bergquist, K.E., Tene, M., Ngadjui, B.T., Ayafor, J.F., Sterner, O., 1995. Cyclodione, an unsymmetrical dimeric diterpene from Cylicodiscus gabunensis. Tetrahedron 51, 11595-11600.

Tasdemir, D., Brun, R., Franzblau, S.G., Sezgin, Y., Calis, I., 2008. Evaluation of antiprotozoal and antimycobacterial activities of the resin glycosides and the other metabolites of Scrophularia cryptophila. Phytomedicine 15, 209-215.

Tchivounda, H.P., Koudogbo, B., Besace, Y., Casadevall, E., 1990. Cylicodiscic Acid, a dihydroxy pentacyclic triterpene carboxylic-acid from Cylicodiscus gabunensis. Phytochemistry 29, 3255-3258.

Tchivounda, H.P., Koudogbo, B., Besace, Y., Casadevall, E., 1991. Triterpene saponins from Cylicodiscus gabunensis. Phytochemistry 30, 2711-2716.

Tene, M., Chabert, P., Note, O., Kenla, T.J.N., Tane, P., Lobstein, A., 2011. Triterpenoid saponins from Cylicodiscus gabunensis. Phytochem Lett 4, 89-92.

Verotta, L., Dell'Agli, M., Giolito, A., Guerrini, M., Cabalion, P., Bosisio, E., 2001. In vitro antiplasmodial activity of extracts of Tristaniopsis species and identification of the active constituents: ellagic acid and 3,4,5-trimethoxyphenyl-(6'-O-galloyl)-O-beta-D-glucopyranoside. J Nat Prod 64, 603607.

World Health Organization. World Malaria Report 2105. http//www.who.int/malaria/publications/worldmalaria-report-2015/en 